\title{
Genetic polymorphisms and haplotypes of ERCC1 and ERCC2 associated with quality of life, depression, and anxiety status among patients with lung cancer
}

Yunxiang Tang ${ }^{\dagger}$, Ruike Zhang ${ }^{\dagger}$, Yinan $\mathrm{Li}^{\dagger}$, Shuyu $\mathrm{Xu}^{\dagger}$, Hao Wang ${ }^{\dagger}$, Jingzhou Xu, Lei Xiao, Yajing Wang, Jing Du, Yujia Huang and Tong Su*

\begin{abstract}
Background: Patients with lung cancer (LC) have a poor quality of life (QoL) and easily suffer from psychological diseases. Previous studies focused less on the relationship between genetic factors and QoL, depression, and anxiety status in LC patients. The current study is intended to explore the relationship between SNPs and haplotypes of ERCC1 and ERCC2 and the QoL, depression and anxiety status of patients with LC.
\end{abstract}

Methods: QoL, depression and anxiety status were assessed in 291 LC patients using the European Organization for Research and Treatment of Cancer (EORTC) Core Quality of Life Questionnaire (QLQ-C30), EORTC Quality of Life Questionnaire-Lung Cancer 13 (QLQ-LC13), SDS and SAS. Nine tag SNPs of ERCC1 and ERCC2 were detected using an improved multiplex ligation detection reaction (iMLDR) technique. Haplotype analysis was conducted using the software Haploview 4.2. The association between SNPs or haplotypes and QoL or depression or anxiety in LC patients was analyzed by regression analysis.

Results: ERCC1 rs11615 was associated with emotional functioning $(P=0.027)$, and ERCC1 rs3212986 was associated with anxiety scores $(P=0.018)$. ERCC1 rs762562-rs3212986 haplotype was associated with cognitive function $(P=0.029)$, somatic function $(P=0.014)$ and dysphagia $(\mathrm{OR}=3.32, P=0.044)$. Patients with ERCC1 rs3212986-rs11615 AG haplotype had worse cognitive function (adjusted Beta $=-5.42$ ) and somatic function (adjusted Beta $=-6.55$ ) and had severer symptoms of loss of appetite (adjusted OR $=1.67$ ) and dysphagia (adjusted $\mathrm{OR}=4.43$ ) (All adjusted $P<0.05$ ). ERCC2 rs13181-rs3916874-rs238416 haplotype was associated with emotional functioning $(P=0.035)$, pain at other sites (OR 1.88, $P=0.014)$, chest pain (OR $0.42, P=0.02)$, dysphagia $(\mathrm{OR} 2.82, P=$ $0.048)$, and anxiety status (OR 0.23, $P=0.009)$.

Conclusion: After adjustment for environmental factors, SNPs and haplotypes of ERCC1 and ERCC2 were associated with different domains of QoL, depression and anxiety in LC patients.

Keywords: ERCC1, ERCC2, Single nucleotide polymorphism, Quality of life, Depression, Anxiety, Lung cancer

\footnotetext{
* Correspondence: sutong-2006@163.com

${ }^{\dagger}$ Yunxiang Tang, Ruike Zhang, Yinan Li, Shuyu Xu and Hao Wang contributed equally to this work.

Department of Medical Psychology, College of Psychology, Naval Medical University, 800 Xiangyin Rd., Shanghai 200433, China
} 


\section{Background}

Lung cancer, as one of the malignant neoplasms, has the highest incidence and mortality rate worldwide. There were 2.1 million lung cancer cases identified in 2018 in the world, accounting for $11.6 \%$ of all cancer cases. 1.8 million lung cancer-related deaths accounted for $18.4 \%$ of all cancer-related deaths [1]. The incidence rate of lung cancer is increasing year by year, and it has become one of the burdens of the major disease in China [2]. Most patients are in their middle or advanced stage at the first diagnosis of lung cancer with a poor prognosis and a low five-year survival rate [3]. Chemotherapy is the main treatment for advanced lung cancer, which is characterized by long treatment cycles and serious adverse reactions. It also causes heavy financial burdens. The physical and mental health and even families of patients are negatively affected. Compared with other tumors, lung cancer patients have a poorer quality of life (QoL) [4]. Therefore, for lung cancer patients, the goal of treatment is not only to improve the survival rate and survival time but also to improve the quality of life of patients with limited survival periods.

QoL refers to the self-evaluated physiological, psychological, and social feelings about the disease and its treatment by patients. The assessment of QoL has important value for clinical research of lung cancer, which can be used to evaluate the therapeutic effect, screen chemotherapy drugs, analyze the prognosis and longterm survival status. According to the systematic review published in Lancet Oncol in 2019, among 44 studies published between 2006 and 2018, the methods used for prognostic factor analysis are more standardized and rigorous than before. Forty-one (93\%) trials reported at least one area of QoL as an independent prognostic factor. The most common prognostic factors were physiological function (17 studies, 39\%) and total health status (15 studies, 34\%). These findings highlight the value of QoL as an independent prognostic factor in cancer research [5]. The basis of improving the QoL is to clarify the influencing factors of QoL with lung cancer. At present, the influencing factors of QoL with lung cancer have not been fully defined.

The QoL of lung cancer is affected by many factors. In the past, most studies focused on demographic, sociological factors, such as gender, age, marriage, and factors of clinical characteristics and treatment. However, the research results of different diseases and different regions are not completely consistent. This may be due to differences in the study population and disease characteristics or other factors (such as genetic factors) that affect the QoL. With the intersection and integration of molecular biology, psychology, and epidemiology, most researchers agree that individual physiology, psychology, and behavior are the result of both genetic and environmental factors. In 2004, Hampton et al. proposed that the QoL has a certain genetic basis, and gene technology should be integrated into the study of QoL $[6,7]$. In 2014, a review summarized the biological pathways, candidate genes, and molecular markers related to the QoL. The results showed that different areas of QoL were related to different pathways. Fatigue was related to inflammatory pathways. The pain was related to inflammation and neural transmission pathways. Depression was related to neurotransmitters and neural plasticity. Oxytocin-related genes and genes related to serotonin and dopamine pathways play a role in social functions [8].

Although more than 50 candidate genes of multiple pathways have been found to be related to pain, fatigue, emotional symptoms, and other areas of QoL, the predictors of QoL in lung cancer have not been fully understood. The function of ERCC1 and ERCC2 genes are closely related to the nucleotide excision repair (NER) pathway of the DNA repair system. There are few studies on the relationship between single nucleotide polymorphisms (SNPs) of ERCC1 and ERCC2 and QoL in lung cancer patients. ERCC1 can form a dimer with xeroderma protein $\mathrm{F}(\mathrm{XPF})$, recognize and remove the mismatch region in the DNA chain, repair and connect the nucleotide fragments after excision, restore the normal DNA structure, which plays an important role in maintaining the stability and integrity of DNA in vivo [9]. ERCC2 is a DNA helicase, which is an integral component of TFIIH, playing an essential role in transcription and NER. The loss of ERCC2 function will lead to the failure of the transcription factor complex to identify DNA damage site and excising and repairing bases accurately, resulting in the accumulation of DNA damage. SNPs of ERCC1 and ERCC2 genes may affect the protein expression level and activity and affect the resection and repairability of the NER system, which are related to lung cancer susceptibility, chemotherapy effect and toxicity of platinum drugs, and prognosis of lung cancer [10-14]. Therefore, ERCC1 and ERCC2 SNPs may be associated with the QoL of lung cancer patients.

The current study is intended to examine the effect of SNPs and haplotypes of ERCC1 and ERCC2 on the QoL, depression and anxiety of LC patients with demographic and clinical characteristics correction. We hope it will provide clues for early identification of patients with poor QoL, depression or anxiety.

\section{Methods}

\section{Subjects}

The subjects of the study were patients with primary lung cancer admitted to the respiratory department of Changhai Hospital Affiliated with Naval Medical University between November 2016 and October 2018. The 
inclusion criteria were: patients (1) were diagnosed with primary lung cancer; (2) could complete the surveys themselves or with help; (3) were aware of their illness conditions. The exclusion criteria were: patients (1) had the pathological type of small cell lung cancer; (2) had been diagnosed with other cancers; (3) with severe psychiatric or somatic illnesses.

This study was approved by the ethics committee of Naval Medical University. Subjects were informed in detail about the experiment and gave their consent. The data of patients used in the current study have been partly used in a previous study addressing associations between QoL and survival of lung cancer patients and the BRCA1 gene [15].

\section{Genotyping}

All SNPs information of ERCC1 and ERCC2 were downloaded from the HapMap database using Haploview4.2 software. The conditions were set as $\mathrm{CHB}, \mathrm{R}^{2}>0.8$, MAF $>0.10$. Three tag SNPs of ERCC1 (rs11615, rs762562, rs3212986) and six tag SNPs of ERCC2 (rs13181, rs171140, rs3916874, rs50872, rs50871, rs238416) were obtained after calculation.

Wizard Genomic DNA Purification Kit (Promega, Madison, Wisconsin, USA) was used to extract genomic DNA. The improved multiplex ligation detection reaction (iMLDR) technique was used to perform SNP genotyping [16].

\section{Assessment of quality of life, anxiety and depression status}

During hospitalization, the demographic, sociological, clinical characteristics and treatment of patients were collected by consulting medical records or interviewing patients. After obtaining the consent of patients, the European Organization for Research and Treatment of Cancer (EORTC) Core Quality of Life Questionnaire (QLQ-C30) and EORTC Quality of Life QuestionnaireLung Cancer 13 (QLQ-LC13) were used to evaluate the quality of life of lung cancer patients. At the same time, the self-rating Anxiety Scale (SAS) [17] and self-rating Depression Scale (SDS) [18] were used to assess the psychological status of patients further.

Both QLQ-C30 and QLQ-LC13 are self-rated questionnaires. The QLQ-C30 comprises 15 scales, including five functional scales (physical, role, cognitive, emotional, and social), three symptom scales (fatigue, pain, and nausea and vomiting), a global health and quality-of-life scale, as well as six single items (dyspnea, appetite loss, sleep disturbance, constipation, and diarrhea), with a total of 30 items [19]. The QLQ-LC13 is a modular supplement to the QLQC30, consisting of 13 items assessing cancer-related symptoms and side effects from cancer treatment. It contains ten symptoms, including shortness of breath, cough, hemoptysis, oral ulcer, dysphagia, peripheral neuropathy, alopecia, chest pain, arm/shoulder pain and pain in other parts [20]. Raw scores of each domain were standardized using linear transformation for comparison. The higher the functional scales and the global health scale, the better the functional status and quality of life. On the contrary, the higher the scores of symptom scales and single items, the more obvious the symptoms and the worse the quality of life.

Both SAS and SDS consist of 20 items scored on a Likert scale of 1 to 4 . The total scores were standardized. SAS standard score $\geq 50$ is considered to have anxiety symptoms, with 50-60 rated as mild anxiety, $61-70$ as moderate anxiety, and $>70$ as severe anxiety [17]. Standard scores $<53$ indicate no depression for the SDS, 53-62 mild, 63-72 moderate, and $>72$ severe depression [18].

\section{Statistical analysis}

Descriptive statistics of patients' general condition, QoL, depression, anxiety, and genotypes were calculated. The scores for the symptom scales and single items of the QoL questionnaire (QLQ-C30 and QLQ-LC13) were skew distribution. According to the scale instructions, the scales were dichotomized as mild symptoms $(<50)$ and severe symptoms $(\geq 50)$, and the frequency of symptoms was calculated [21].

Linkage disequilibrium analysis of all tag SNPs in the genes was performed with Haploview v4.2 [22] to obtain statistically associated SNPs -- haplotypes. The main model of association analysis is the additive model, which takes major alleles or major haplotypes as reference. In addition to the additive model, the dominant model was used in exploring associations between a single SNP and Quality of Life. Linear regression analysis was used to analyze SNP or haplotype and continuous variables (scores of functional scales, global health scale, SAS and SDS). Logistic regression analysis was used for association analysis between SNP or haplotype and dichotomized variables (symptoms, single items and status of depression and anxiety). The environmental factors were included in regression models as covariates for adjustment, including sex, age, occupation, marriage, education, number of children, smoking history, drinking history, medical insurance, pathological types, clinical stages, metastasis, concurrent symptoms, operation history, and chemotherapy. Statistical significance was corrected with Bonferroni methods. Statistical analyses were performed with SPSS 25.0 (Chicago, IL, USA). All statistical tests were performed using a two-sided probability test, and differences were considered statistically significant at $P<0.05$. 


\section{Results}

\section{Patient characteristics}

The final number of lung cancer patients included in the statistical analysis was 291. The age ranged from 24 to 89 years, with a mean age of $60.02 \pm 10.94$ years and $59.1 \%$ of those $\geq 60$ years. There were 203 males $(69.8 \%)$. The vast majority were married $(94.8 \%)$, most had only one child (62.9\%), and most had a history of smoking (74.9\%) and alcohol consumption (74.2\%). The subjects were all patients with non-small cell lung cancer, with the main types of pathology being adenocarcinoma (47.8\%) and squamous carcinoma (21.6\%), and the main clinical stages being stage IV $(66.7 \%)$ and stage III (24.1\%). Most patients $(98.3 \%)$ received chemotherapy without surgery. 187 (64.3\%) patients had less than four sessions of chemotherapy, and 104 (35.7\%) patients had four or more sessions of chemotherapy. Patients received mainly platinum-based chemotherapy regimens in cycles of 3 to 4 weeks. These patients have not been treated with targeted therapies or immunotherapy.

Patient information was described in detail in a previous study [15].

\section{SNPs and haplotypes}

The distribution of tagSNPs genotypes of ERCC1 and ERCC2 are shown in (Table 1). Three SNP combinations of ERCC1 and ERCC2 were obtained by linkage disequilibrium analysis: ERCC1 rs762562-rs3212986, ERCC1 rs3212986-rs11615, ERCC2 rs13181-rs3916874-rs238416 (Table 2). The haplotypes with the largest number were used as a reference for subsequent analysis.

\section{Quality of life and depression and anxiety status}

The standardized scores of the 291 study participants for each domain of the quality of life scale were mostly close to the reference value "EORTC QLQ-C30 Reference Values" [21], but the score for the economic hardship domain $($ mean $=53.38, \quad \mathrm{SD}=36.92)$ was significantly higher than the reference values (mean $=17.4, \mathrm{SD}=$ 28.9). The scores of the study subjects were described in detail in the previous study [15].

Because of the skewed distribution of symptom scores, a cut-off of 50 was converted to a dichotomous variable (symptom light and symptom heavy) for subsequent analysis. The number and proportion of symptom heaviness were: C30 fatigue symptom heaviness 79 (27.1\%), C30 nausea and vomiting symptom heaviness 59 (20.3\%), C30 pain symptom heaviness 84 (28.9\%), C30 shortness of breath symptom heaviness 73 (25.1\%), C30 insomnia symptom heaviness 87 (29.9\%), C30 loss of appetite symptom heaviness 82 (28.2\%), C30 constipation in 59 (20.3\%), C30 diarrhea in 17 (5.8\%), C30 economic difficulties in 144 (49.5\%), LC13 cough in 71 (24.4\%), LC13 hemoptysis in 19 (6.5\%), LC13 shortness of breath
Table 1 Genotype distribution of tagSNPs in ERCC1 and ERCC2

\begin{tabular}{|c|c|c|c|}
\hline Gene & SNPs & $n$ & $\%$ \\
\hline \multirow[t]{4}{*}{ ERCC1 } & rs11615 & & \\
\hline & GG (CC) & 159 & 54.6 \\
\hline & $\mathrm{GA}(\mathrm{CT})$ & 115 & 39.5 \\
\hline & $\mathrm{AA}(\mathrm{TT})$ & 17 & 5.8 \\
\hline \multirow[t]{4}{*}{ ERCC1 } & rs762562 & & \\
\hline & $\mathrm{AA}$ & 95 & 32.6 \\
\hline & GA & 148 & 50.9 \\
\hline & GG & 48 & 16.5 \\
\hline \multirow[t]{4}{*}{ ERCC1 } & rs3212986 & & \\
\hline & $\mathrm{CC}$ & 125 & 43.0 \\
\hline & $C A$ & 140 & 48.1 \\
\hline & $\mathrm{AA}$ & 26 & 8.9 \\
\hline \multirow[t]{4}{*}{ ERCC2 } & rs13181 & & \\
\hline & $\pi$ & 245 & 84.2 \\
\hline & GT & 43 & 14.8 \\
\hline & GG & 3 & 1.0 \\
\hline \multirow[t]{4}{*}{ ERCC2 } & rs171140 & & \\
\hline & $\mathrm{AA}$ & 86 & 29.6 \\
\hline & $C A$ & 140 & 48.1 \\
\hline & CC & 65 & 22.3 \\
\hline \multirow[t]{4}{*}{ ERCC2 } & rs238416 & & \\
\hline & CC & 82 & 28.2 \\
\hline & $C T$ & 152 & 52.2 \\
\hline & $\Pi$ & 57 & 19.6 \\
\hline \multirow[t]{4}{*}{ ERCC2 } & rs3916874 & & \\
\hline & $\mathrm{CC}$ & 192 & 66.0 \\
\hline & GC & 87 & 29.9 \\
\hline & GG & 12 & 4.1 \\
\hline \multirow[t]{4}{*}{ ERCC2 } & rs50871 & & \\
\hline & $\mathrm{AA}$ & 143 & 49.1 \\
\hline & CA & 120 & 41.2 \\
\hline & CC & 28 & 9.6 \\
\hline \multirow[t]{4}{*}{ ERCC2 } & rs50872 & & \\
\hline & GG & 194 & 66.7 \\
\hline & GA & 88 & 30.2 \\
\hline & AA & 9 & 3.1 \\
\hline
\end{tabular}

in 38 (13.1\%), LC13 mouth ulcer in 18 (6.2\%), LC13 dysphagia $14(4.8 \%)$, LC13 peripheral neuropathy $24(8.2 \%)$, LC13 alopecia 45 (15.5\%), LC13 chest pain 50 (17.2\%), LC13 arm/shoulder pain 50 (17.2\%), LC13 pain at other sites 49 (16.8\%).

The mean score (standardized score, mean \pm SD) on the SDS scale was $52.28 \pm 11.69$, and the mean score (standardized score, mean $\pm \mathrm{SD}$ ) on the SAS scale was $43.49 \pm 9.13$ in 291 study subjects. 142 (48.8\%) patients 
Table 2 Haplotypes of ERCC1, ERCC2 gene

\begin{tabular}{lllll}
\hline Gene & SNPs & Haplotype & Quantity & Frequency* \\
\hline ERCC1 & rs762562-rs3212986 & GC (ref) & 243 & 0.4175 \\
ERCC1 & rs762562-rs3212986 & AA & 191 & 0.3282 \\
ERCC1 & rs762562-rs3212986 & AC & 147 & 0.2526 \\
ERCC1 & rs3212986-rs11615 & CG (ref) & 242 & 0.4158 \\
ERCC1 & rs3212986-rs11615 & AG & 191 & 0.3282 \\
ERCC1 & rs3212986-rs11615 & CA & 148 & 0.2543 \\
ERCC2 & rs13181-rs3916874-rs238416 & TCT (ref) & 266 & 0.4570 \\
ERCC2 & rs13181-rs3916874-rs238416 & TCC & 156 & 0.2680 \\
ERCC2 & rs13181-rs3916874-rs238416 & TGC & 111 & 0.1907 \\
ERCC2 & rs13181-rs3916874-rs238416 & GCC & 49 & 0.0842
\end{tabular}

Note: when calculating the frequency, the numerator $=$ the corresponding number of haplotype, denominator $=2{ }^{*}$ sample size. ${ }^{*}$ means multiplication

had a depressive state, and 67 (23.0\%) patients had an anxious state, of whom most were mild depression (102/ $142)$, and mild anxiety (58/67), and depression and anxiety were significantly correlated $(p<0.001), 38.0 \%(54 /$ 142) of the depressed patients had a comorbid anxiety state and $80.6 \%(54 / 67)$ of the anxious patients had a comorbid depression state.
The association of SNPs to the quality of life, depression and anxiety

Both ERCC1 and ERCC2 have SNP loci associated with quality of life, anxiety and depression in lung cancer, mainly focusing on ERCC1rs11615 and rs3212986, associated with multiple domains of quality of life (Table 3).

Table 3 Associations between single SNP of ERCC1 and ERCC2 gene and Quality of Life, depression and anxiety (unadjusted and adjusted for Environmental factors)

\begin{tabular}{|c|c|c|c|c|c|c|c|c|c|c|}
\hline \multirow[t]{2}{*}{ Area } & \multirow[t]{2}{*}{ SNP } & \multirow[t]{2}{*}{ Gene } & \multirow{2}{*}{$\begin{array}{l}\text { Ref/ } \\
\text { Alt }\end{array}$} & \multirow[t]{2}{*}{ Model } & \multirow{2}{*}{$\begin{array}{l}\text { Beta }(95 \% \mathrm{Cl}) \\
\text { a or } \\
\text { OR }(95 \% \mathrm{Cl})^{b}\end{array}$} & \multirow[t]{2}{*}{$P$} & \multirow{2}{*}{$\begin{array}{l}\text { Bofferoni } \\
\text { adjusted }\end{array}$} & \multicolumn{3}{|c|}{ Environmental factors correction } \\
\hline & & & & & & & & $\begin{array}{l}\text { Beta }(95 \% \mathrm{Cl}) \\
{ }^{\mathrm{a}} \text { or } \\
\text { OR }(95 \% \mathrm{Cl})^{\mathrm{b}}\end{array}$ & $P$ & $\begin{array}{l}\text { Bofferoni } \\
\text { adjusted }\end{array}$ \\
\hline C30 Emotional functions & rs11615 & ERCC1 & $G / A$ & Additive & $6.34(2.09-10.59)$ & 0.004 & 0.036 & $6.85(2.38-11.31)$ & 0.003 & 0.027 \\
\hline C30 Fatigue & rs11615 & ERCC1 & $G / A$ & Additive & $0.62(0.39-0.98)$ & 0.041 & 0.369 & - & - & - \\
\hline LC13 Dysphagia & rs11615 & ERCC1 & $G / A$ & Additive & $0.20(0.047-0.88)$ & 0.033 & 0.297 & $0.18(0.04-0.87)$ & 0.033 & 0.297 \\
\hline $\begin{array}{l}\text { SAS Anxiety standard } \\
\text { score }\end{array}$ & rs11615 & ERCC1 & $G / A$ & Additive & $\begin{array}{l}-1.94(-3.66-- \\
0.22)\end{array}$ & 0.028 & 0.252 & $\begin{array}{l}-2.06(-3.85-- \\
0.27)\end{array}$ & 0.025 & 0.225 \\
\hline C30 Cognitive functions & rs3212986 & ERCC1 & $C / A$ & Additive & $\begin{array}{l}-5.72(-10.15-- \\
1.31)\end{array}$ & 0.012 & 0.108 & $\begin{array}{l}-6.18(-10.74-- \\
1.62)\end{array}$ & 0.008 & 0.072 \\
\hline C30 Physical functions & rs3212986 & ERCC1 & $C / A$ & Additive & $\begin{array}{l}-5.43(-9.68-- \\
1.18)\end{array}$ & 0.013 & 0.117 & $\begin{array}{l}-5.98(-10.40-- \\
1.56)\end{array}$ & 0.008 & 0.072 \\
\hline C30 Fatigue & rs3212986 & ERCC1 & $\mathrm{C} / \mathrm{A}$ & Additive & $1.52(1.02-2.28)$ & 0.042 & 0.378 & - & - & - \\
\hline LC13 Dysphagia & rs3212986 & ERCC1 & $C / A$ & Additive & $2.31(1.02-5.22)$ & 0.045 & 0.405 & $4.87(1.43-16.62)$ & 0.011 & 0.099 \\
\hline $\begin{array}{l}\text { SDS depression standard } \\
\text { score }\end{array}$ & rs3212986 & ERCC1 & $\mathrm{C} / \mathrm{A}$ & Dominant & $3.07(0.37-5.77)$ & 0.026 & 0.234 & $2.96(0.21-5.71)$ & 0.036 & 0.324 \\
\hline $\begin{array}{l}\text { SAS Anxiety standard } \\
\text { score }\end{array}$ & rs3212986 & ERCC1 & $C / A$ & Dominant & $3.09(1.00-5.18)$ & 0.004 & 0.036 & $3.41(1.23-5.57)$ & 0.002 & 0.018 \\
\hline SAS Anxiety State & rs3212986 & ERCC1 & $\mathrm{C} / \mathrm{A}$ & Dominant & $1.90(1.06-3.39)$ & 0.030 & 0.270 & $2.03(1.11-3.73)$ & 0.022 & 0.198 \\
\hline LC13 Pain in other parts & rs762562 & $\mathrm{ERCC} 1$ & $A / G$ & Additive & $1.60(1.02-2.51)$ & 0.042 & 0.378 & $1.73(1.04-2.86)$ & 0.034 & 0.306 \\
\hline LC13 Chest pain & rs3916874 & ERCC2 & $C / G$ & Additive & $0.48(0.25-0.93)$ & 0.029 & 0.261 & - & - & - \\
\hline SAS Anxiety State & rs13181 & ERCC2 & $\mathrm{T} / \mathrm{G}$ & Dominant & $0.28(0.095-0.80)$ & 0.018 & 0.162 & $0.22(0.07-0.66)$ & 0.007 & 0.063 \\
\hline
\end{tabular}

Ref/Alt:Refer to allele (wild-type allele) / mutant allele. Model:Additive model or Dominant model. Covariates refer to environmental factors including:sex, age, occupation, marriage, education, number of children, smoking history, drinking history, medical insurance, pathological types, clinical stages, metastasis, concurrent symptoms, operation history, and chemotherapy. ${ }^{\text {a }} \beta$ and $95 \%$ confidence interval (Cl) were reported (Linear regression was used for general health condition and functioning domains, anxiety and depression). ${ }^{\mathrm{b}}$ odds ratio $(O R)$ and $95 \% \mathrm{Cl}$ were reported (Logistic regression was used for symptoms domains, anxiety and depression) 
However, after adjustment for environmental factors and multiple tests (Bonferroni adjusted), only ERCC1 rs11615 was significantly associated with emotional function (environment adjusted beta $=6.85,95 \% \mathrm{CI}=$ 2.38-11.31, Bonferroni adjusted $P=0.027$ ), and ERCC1 rs3212986 was significantly correlated with anxiety score (environment adjusted beta $=3.41,95 \% \mathrm{CI}=1.23-5.57$, Bonferroni adjusted $P=0.018$ ). In other words, patients with ERCC1 rs11615 A allele had a better emotional function, while patients with ERCC1 rs3212986 A allele had severer anxiety than those without the allele.

\section{The Association of Haplotypes to the quality of life, depression and anxiety}

Both ERCC1 and ERCC2 haplotypes are associated with multiple domains of quality of life in lung cancer patients (Table 4).

ERCC1 rs762562-rs3212986 haplotype is associated with cognitive function, somatic function and dysphagia. Compared with GC haplotype, ERCC1 rs762562rs3212986 AA haplotype was significantly associated with worse cognitive function (adjusted beta $=-5.34$, 95\% CI $=-10.13-0.56$, adjusted $P=0.029$ ), somatic function (adjusted beta $=-5.89,95 \% \mathrm{CI}=-5.89,95 \% \mathrm{CI}=-$ $10.53-1.25$, adjusted $P=0.014$ ), and severer in dysphagia symptoms (adjusted OR $=3.32,95 \% \mathrm{CI}=1.03-10.66$, adjusted $P=0.044$ ) after correction for environmental factors, indicating that ERCC1 rs762562-rs3212986 AA haplotype is a risk factor for quality of life in lung cancer patients.

ERCC1 rs3212986-rs11615 haplotype was associated with emotional function, cognitive function, somatic function, loss of appetite, dysphagia and anxiety scores. After adjustment for environmental factors, compared with CG haplotype, patients with ERCC1 rs3212986rs11615 AG haplotype had worse cognitive function (adjusted Beta $=-5.42$, adjusted $P=0.028$ ) and somatic function (adjusted Beta $=-6.55$, adjusted $P=0.007$ ), and had severer symptoms of loss of appetite (adjusted OR = 1.67, adjusted $P=0.025$ ) and dysphagia (adjusted $\mathrm{OR}=$ 4.43, adjusted $P=0.019$ ), which indicated that ERCC1 rs3212986-rs11615 AG haplotype is a risk factor of quality of life in patients with lung cancer. On the other hand, compared with CG haplotype, ERCC1 rs3212986rs11615 CA haplotype were associated with better emotional functions (adjusted Beta $=6.61$, adjusted $P=$ 0.005 ), mild dysphagia (adjusted $\mathrm{OR}=0.035$, adjusted $P=0.017$ ), and lower anxiety score (adjusted Beta $=-$ 2.18 , adjusted $P=0.023$ ) after environmental factors corrections, suggesting that ERCC1 CA haplotype is a protective factor of quality of life and anxiety in patients with lung cancer.

ERCC2 rs13181-rs3916874-rs238416 haplotype was associated with emotional function, pain in other parts, chest pain, dysphagia and anxiety. After adjusting for environmental factors, GCC haplotype compared with the TCT haplotype was correlated with better emotional function (adjusted beta $=7.60$, adjusted $P=0.035$ ) and lower anxiety risk (adjusted $\mathrm{OR}=0.23$, adjusted $P=$ 0.009). In addition, chest pain was mild in patients with a copy of the TGC haplotype (adjusted $\mathrm{OR}=0.42$, adjusted $P=0.02$ ). In contrast, severe pain in other parts (adjusted $\mathrm{OR}=1.88$, adjusted $P=0.014$ ) and dysphagia (adjusted $\mathrm{OR}=2.82$, adjusted $P=0.048$ ) were more severe in lung cancer patients with TGC haplotype.

\section{Discussion}

According to the 2015 National Comprehensive Cancer Network (NCCN) guidelines for the treatment of nonsmall cell lung cancer, platinum-based chemotherapy is the first-line treatment for patients with advanced lung cancer [23]. Platinum drugs play an anti-tumor role mainly through the introduction of intra-chain and inter-chain cross-linking to destroy tumor cell DNA, leading to cell death [24]. Resistance to platinum-based drugs often leads to a poor prognosis. DNA repair pathway is the key molecular mechanism of resistance to platinum-based drugs. ERCC1 and ERCC2 play an indispensable role in the NER pathway of DNA repair and are related to clinical therapeutic effects and prognosis $[12,14]$.

ERCC1 activity was affected by ERCC1 gene polymorphism. Among the polymorphisms related to the absorption, metabolism, cytotoxicity, and excretion of platinum drugs, ERCC1 gene C118T (rs11615) and C8092A (rs3212986) is the most predictive characteristic SNP. A systematic review on gene variation and cisplatin toxicity showed that ERCC1 rs11615, rs3212986, and ERCC2 rs13181 were associated with cisplatin nephrotoxicity [25]. However, due to the heterogeneity of the researchers and the difference in chemotherapy regimens, the results of many studies on the predictive ability of ERCC1 polymorphism are not consistent [24]. At present, there are few studies on the effect of ERCC1 gene polymorphism on the quality of life of lung cancer patients.

The results showed that ERCC1 rs11615 was significantly correlated with emotional function (environment adjusted beta $=6.85$, Bonferroni adjusted $P=0.027$ ), and ERCC1 rs3212986 was significantly correlated with anxiety score (environment adjusted beta $=3.41$, Bonferroni adjusted $P=0.018$ ). In other words, patients with ERCC1 rs11615 A allele had better emotional functions, while patients with ERCC1 rs3212986 A allele had severer anxiety than those with the allele. Studies have shown that patients with ERCC1 rs11615 AA have better chemotherapy effects and longer progression-free survival, while patients with A allele of ERCC1 rs3212986 
Table 4 Associations between ERCC1 and ERCC2 gene haplotypes and Quality of Life, depression and anxiety (unadjusted and adjusted for Environmental factors)

\begin{tabular}{|c|c|c|c|c|c|c|c|}
\hline \multirow[t]{2}{*}{ Area } & \multirow[t]{2}{*}{ Gene } & \multirow[t]{2}{*}{ SNPs } & \multirow[t]{2}{*}{ Haplotype } & \multirow[t]{2}{*}{$P$} & \multirow{2}{*}{$\begin{array}{l}\text { Beta }(95 \% \mathrm{Cl})^{a} \text { or } \\
\text { OR }(95 \% \mathrm{Cl})^{\mathrm{b}}\end{array}$} & \multicolumn{2}{|c|}{ Environmental factors correction } \\
\hline & & & & & & $\bar{P}$ & $\begin{array}{l}\text { Beta }(95 \% \mathrm{Cl})^{\mathrm{a}} \text { or } \\
\text { OR }(95 \% \mathrm{Cl})^{\mathrm{b}}\end{array}$ \\
\hline \multirow[t]{3}{*}{ C30 Cognitive functions } & ERCC1 & rs762562-rs3212986 & AA & 0.038 & $-4.87(-9.45--0.29)$ & 0.029 & $-5.34(-10.13--0.56)$ \\
\hline & & & $A C$ & 0.058 & $4.66(-0.14-9.47)$ & 0.083 & $4.47(-0.56-9.50)$ \\
\hline & & & GC (ref) & - & - & - & - \\
\hline \multirow[t]{3}{*}{ C30 Physical functions } & ERCC1 & rs762562-rs3212986 & AA & 0.019 & $-5.33(-9.75--0.90)$ & 0.014 & $-5.89(-10.53--1.25)$ \\
\hline & & & $A C$ & 0.239 & $2.77(-1.83-7.38)$ & 0.202 & $3.22(-1.71-8.14)$ \\
\hline & & & GC (ref) & - & - & - & - \\
\hline \multirow[t]{3}{*}{ LC13 Dysphagia } & ERCC1 & rs762562-rs3212986 & AA & 0.165 & $1.80(0.79-4.10)$ & 0.044 & $3.32(1.03-10.66)$ \\
\hline & & & $A C$ & 0.063 & $0.31(0.09-1.06)$ & 0.133 & $0.33(0.08-1.40)$ \\
\hline & & & GC (ref) & - & - & - & - \\
\hline \multirow[t]{3}{*}{ C30 Emotional functions } & ERCC1 & rs3212986-rs11615 & $A G$ & 0.490 & $-1.52(-5.83-2.79)$ & 0.490 & $-1.59(-6.12-2.93)$ \\
\hline & & & $C A$ & 0.007 & $6.04(1.72-10.36)$ & 0.005 & $6.61(2.08-11.15)$ \\
\hline & & & CG (ref) & - & - & - & - \\
\hline \multirow[t]{3}{*}{ C30 Cognitive functions } & ERCC1 & rs3212986-rs11615 & $A G$ & 0.027 & $-5.27(-9.90--0.63)$ & 0.028 & $-5.42(-10.24--0.60)$ \\
\hline & & & $C A$ & 0.075 & $4.38(-0.43-9.19)$ & 0.060 & $4.77(-0.18-9.72)$ \\
\hline & & & CG (ref) & - & - & - & - \\
\hline \multirow[t]{3}{*}{ C30 Physical functions } & ERCC1 & rs3212986-rs11615 & $A G$ & 0.009 & $-6.06(-10.55--1.57)$ & 0.007 & $-6.55(-11.24--1.86)$ \\
\hline & & & $C A$ & 0.178 & $3.17(-1.43-7.77)$ & 0.125 & $3.80(-1.04-8.65)$ \\
\hline & & & CG (ref) & - & - & - & - \\
\hline \multirow[t]{3}{*}{ C30 Appetite loss } & ERCC1 & rs3212986-rs11615 & $A G$ & 0.037 & $1.57(1.03-2.40)$ & 0.025 & $1.67(1.07-2.61)$ \\
\hline & & & CA & 0.708 & $1.09(0.70-1.68)$ & 0.956 & $0.99(0.62-1.57)$ \\
\hline & & & CG (ref) & - & - & - & - \\
\hline \multirow[t]{3}{*}{ LC13 Dysphagia } & ERCC1 & rs3212986-rs11615 & $A G$ & 0.068 & $2.18(0.94-5.05)$ & 0.019 & $4.43(1.28-15.39)$ \\
\hline & & & CA & 0.027 & $0.19(0.04-0.82)$ & 0.035 & $0.17(0.032-0.88)$ \\
\hline & & & CG (ref) & - & - & - & - \\
\hline \multirow[t]{3}{*}{ SAS Anxiety standard score } & ERCC1 & rs3212986-rs11615 & $A G$ & 0.130 & $1.34(-0.39-3.07)$ & 0.076 & $1.63(-0.16-3.41)$ \\
\hline & & & CA & 0.014 & $-2.25(-4.02--0.47)$ & 0.023 & $-2.18(-4.05--0.32)$ \\
\hline & & & CG (ref) & - & - & - & - \\
\hline \multirow[t]{4}{*}{ C30 Emotional functions } & ERCC2 & rs13181-rs3916874-rs238416 & GCC & 0.047 & $6.81(0.125-13.50)$ & 0.035 & $7.60(0.60-14.61)$ \\
\hline & & & TCC & 0.411 & $-1.75(-5.91-2.42)$ & 0.248 & $-2.60(-7.00-1.80)$ \\
\hline & & & TGC & 0.199 & $3.17(-1.66-8.01)$ & 0.124 & $4.00(-1.08-9.09)$ \\
\hline & & & $\mathrm{TCT}$ (ref) & - & - & - & - \\
\hline \multirow[t]{4}{*}{ LC13 Chest pain } & ERCC2 & rs13181-rs3916874-rs238416 & GCC & 0.899 & $0.95(0.45-2.03)$ & 0.712 & $1.18(0.50-2.77)$ \\
\hline & & & TCC & 0.705 & $1.09(0.69-1.74)$ & 0.736 & $1.10(0.64-1.86)$ \\
\hline & & & TGC & 0.018 & $0.44(0.22-0.87)$ & 0.020 & $0.42(0.21-0.87)$ \\
\hline & & & TCT (ref) & - & - & - & - \\
\hline \multirow[t]{4}{*}{ LC13 Pain in other parts } & ERCC2 & rs13181-rs3916874-rs238416 & GCC & 0.367 & $0.66(0.27-1.61)$ & 0.198 & $0.52(0.19-1.41)$ \\
\hline & & & TCC & 0.042 & $1.59(1.02-2.50)$ & 0.014 & $1.88(1.14-3.12)$ \\
\hline & & & TGC & 0.093 & $0.57(0.29-1.10)$ & 0.145 & $0.58(0.28-1.21)$ \\
\hline & & & TCT (ref) & - & - & - & - \\
\hline \multirow[t]{3}{*}{ LC13 Dysphagia } & ERCC2 & rs13181-rs3916874-rs238416 & GCC & 0.491 & $0.49(0.06-3.73)$ & 0.546 & $0.44(0.03-6.32)$ \\
\hline & & & TCC & 0.062 & $2.10(0.96-4.55)$ & 0.048 & $2.82(1.01-7.85)$ \\
\hline & & & TGC & 0.758 & $1.18(0.42-3.33)$ & 0.451 & $0.60(0.16-2.28)$ \\
\hline
\end{tabular}


Table 4 Associations between ERCC1 and ERCC2 gene haplotypes and Quality of Life, depression and anxiety (unadjusted and adjusted for Environmental factors) (Continued)

\begin{tabular}{|c|c|c|c|c|c|c|c|}
\hline \multirow[t]{2}{*}{ Area } & \multirow[t]{2}{*}{ Gene } & \multirow[t]{2}{*}{ SNPs } & \multirow[t]{2}{*}{ Haplotype } & \multirow[t]{2}{*}{$P$} & \multirow{2}{*}{$\begin{array}{l}\text { Beta }(95 \% \mathrm{Cl})^{\mathrm{a}} \text { or } \\
\text { OR }(95 \% \mathrm{Cl})^{\mathrm{b}}\end{array}$} & \multicolumn{2}{|c|}{ Environmental factors correction } \\
\hline & & & & & & $P$ & $\begin{array}{l}\text { Beta }(95 \% \mathrm{Cl})^{\mathrm{a}} \text { or } \\
\text { OR }(95 \% \mathrm{Cl})^{\mathrm{b}}\end{array}$ \\
\hline & & & TCT (ref) & - & - & - & - \\
\hline \multirow[t]{4}{*}{ SAS Anxiety state } & ERCC2 & rs13181-rs3916874-rs238416 & GCC & 0.018 & $0.28(0.10-0.80)$ & 0.009 & $0.23(0.08-0.69)$ \\
\hline & & & TCC & 0.401 & $1.20(0.79-1.81)$ & 0.479 & $1.18(0.75-1.85)$ \\
\hline & & & TGC & 0.188 & $0.70(0.41-1.19)$ & 0.211 & $0.69(0.39-1.23)$ \\
\hline & & & TCT (ref) & - & - & - & - \\
\hline
\end{tabular}

Covariates refer to environmental factors including:sex, age, occupation, marriage, education, number of children, smoking history, drinking history, medical insurance, pathological types, clinical stages, metastasis, concurrent symptoms, operation history, and chemotherapy

When calculating the frequency, the molecule $=$ the corresponding haplotype number, the denominator of the reference haplotype $=2 *$ (the sample number that contains the reference haplotype), the denominator of none reference haplotype $=2 *$ (the sample number that contains the reference and the current haplotypes). * means multiplication

${ }^{a} \beta$ and $95 \%$ confidence interval $(C l)$ were reported (Linear regression was used for general health condition and functioning domains, anxiety and depression).

bodds ratio $(O R)$ and $95 \% \mathrm{Cl}$ were reported (Logistic regression was used for symptoms domains, anxiety and depression)

have a poor response to chemotherapy and shorter progression-free survival $[26,27]$. It may be because the lung cancer patients with ERCC1 rs11615 A allele have better chemotherapy effects and longer survival time, which is conducive to maintain a good emotional state, so it reflects better emotional function and quality of life. However, the patients with ERCC1 rs3212986 A allele could not effectively relieve the symptoms due to poor chemotherapy effect, and their cognitive and physical functions were affected, which led to a higher anxiety level.

Previous studies on tumor susceptibility found that although single SNPs were not significantly associated with tumor risk, haplotypes containing one or more functional SNPs have significant associations with tumor susceptibility [13]. For example, two haplotypes containing the ERCC2 rs3916874 G allele were closely related to the risk of lung cancer, rs13181-rs3916874-rs238415 AGG haplotypes are associated with an increased risk of pancreatic cancer [28]. Studies on SNP and chemotherapy adverse reactions also found that the combination of genetic markers may be a better at-risk prediction [29]. In this study, although the correlation between a single ERCC2 SNP and quality of life was not significant after multiple test correction, the haplotype rs13181rs3916874-rs238416 composed of three tagSNPs of ERCC2 gene was significantly associated with some areas of quality of life in patients with lung cancer. GCC haplotype was found to be correlated with better emotional function and lower anxiety risk. Lighter chest pain symptoms were found in patients with the TGC haplotype, while pain in other parts and dysphagia were severe in patients with TCC haplotype. ERCC1 rs3212986rs11615 AG haplotype was associated with poor cognitive function and somatic function, severe symptoms of loss of appetite, and dysphagia, while LC patients having a copy of CA haplotype had better emotional functions, mild dysphagia, and lower anxiety score. ERCC1 rs762562-rs3212986 AA haplotype was found to be significantly correlated with poor cognitive and somatic functions and severe dysphagia. These results may reflect the correlation of polymorphisms and haplotypes of different genes with various domains of quality of life and suggest their significance in predicting the quality of life and prognosis of patients.

Neuropsychologic abnormalities such as anxiety and depression are common in cancer patients [30]. The study results showed that $48.8 \%$ of lung cancer patients had depression, $23.0 \%$ of patients had anxiety, most were mild depression (102/142) and mild anxiety (58/67). And depression and anxiety were significantly correlated. There is increasing evidence that genetic polymorphisms may lead to different susceptibility to psychoneurosis [31]. Catechol-O-methyltransferase (COMT) polymorphism is associated with anxiety symptoms in breast cancer patients [32]. Brain-derived neurotrophic factor (BDNF) Val66Met polymorphism was significantly correlated with anxiety in patients with advanced gastric cancer [33]. Polymorphisms in the 5-hydroxytryptamine transporter gene-linked polymorphism region (5-HTTL PR) were associated with anxiety and depression in breast cancer patients [34, 35]. This study showed that ERCC1 rs3212986, ERCC1 rs3212986-rs11615, ERCC2 rs13181-rs3916874-rs238416 were associated with anxiety or depression in LC patients. These factors may help screen out lung cancer patients with a higher risk of anxiety and depression to carry out a personalized intervention.

The limitation of this study is that there is no accurate information about the evaluation of chemotherapy effect and tissue samples of patients, so it is impossible to explore the relationship between SNPs and chemotherapy effect or protein expression level of lung cancer, which limits the exploration of the underlying mechanisms of 
the association between ERCC1, ERCC2 SNPs, haplotypes, and quality of life of LC patients. A further study with more focus on the mechanism behind this association is therefore suggested. Furthermore, for complex phenotypes, the influence of genetic factors may be the synergistic effect of multiple SNPs or even the influence of multiple gene pathways. Therefore, these nine SNPs loci may not fully reflect the impact of genetic factors on the quality of life of lung cancer patients.

\section{Conclusion}

SNPs and haplotypes of ERCC1 and ERCC2 were associated with different domains of QoL, depression and anxiety in LC patients.

As few studies have explored the genetic factors affecting the quality of life, we first proposed the correlation between ERCC1, ERCC2 gene polymorphisms, and the quality of life of lung cancer patients, which provides a new perspective for the study of LC patients' quality of life.

\footnotetext{
Abbreviations

EORTC: European organization for research and treatment of cancer; ERCC1: Excision repair cross-complementing 1; ERCC2: Excision repair crosscomplementing 2; iMLDR: Improved multiplex ligation detection reaction; LC: Lung cancer; NER: Nucleotide excision repair; OR: Odds ratio; QLQC30: Core quality of life questionnaire; QLQ-LC13: Quality of Life Questionnaire-Lung Cancer 13; QoL: Quality of life; SNP: Single nucleotide polymorphism; tag SNPs: Tag single nucleotide polymorphism
}

\section{Supplementary Information}

The online version contains supplementary material available at https://doi. org/10.1186/s12885-021-08570-5.

Additional file 1.

\section{Acknowledgments}

Not applicable.

\section{Authors' contributions}

YXT, RKZ and YNL contributed to experimental operation, data collection and analysis, and wrote the first draft. SYX, HW, and JZX contributed to questionnaire survey. LX, YJW, JD and YJH contributed to follow-up. TS supervised data collection and analysis critically read and revised this manuscript and takes the responsibility of this paper. All authors meet authorship criteria and approve the final version of the manuscript.

\section{Funding}

This study was funded by "National Science Foundation of China" (Grant Number 81602734).

\section{Availability of data and materials}

The datasets used and/or analyzed during the current study are available from the corresponding author on reasonable request.

\section{Declarations}

\section{Ethics approval and consent to participate}

Approval was obtained from the ethics committee of Navy Medical University, China. The procedures used in this study adhere to the tenets of the Declaration of Helsinki. Informed consent was obtained from all individual participants included in the study.
Consent for publication

Not applicable.

\section{Competing interests}

All authors declare that they have no competing interests.

Received: 27 March 2021 Accepted: 18 June 2021

Published online: 21 July 2021

\section{References}

1. Bray F, Ferlay J, Soerjomataram I, Siegel RL, Torre LA, Jemal A. Global cancer statistics 2018: GLOBOCAN estimates of incidence and mortality worldwide for 36 cancers in 185 countries. CA Cancer J Clin. 2018;68(6):394-424. https://doi.org/10.3322/caac.21492.

2. Guo H, Chang Z, Wu J, Li W. Air pollution and lung cancer incidence in China: who are faced with a greater effect? Environ Int. 2019;132:105077. https://doi.org/10.1016/j.envint.2019.105077.

3. Hirsch FR, Scagliotti GV, Mulshine JL, Kwon R, Curran WJ Jr, Wu YL, et al. Lung cancer: current therapies and new targeted treatments. Lancet. 2017; 389(10066):299-311. https://doi.org/10.1016/S0140-6736(16)30958-8.

4. Yang P, Cheville AL, Wampfler JA, Garces YI, Jatoi A, Clark MM, et al. Quality of life and symptom burden among long-term lung Cancer survivors. J Thorac Oncol. 2012;7(1):64-70. https://doi.org/10.1097/JTO.0b013e31823 97b3e.

5. Mierzynska J, Piccinin C, Pe M, Martinelli F, Gotay C, Coens C, et al. Prognostic value of patient-reported outcomes from international randomised clinical trials on cancer: a systematic review. Lancet Oncol. 2019;20(12):E685-98. https://doi.org/10.1016/S1470-2045(19)30656-4.

6. Hampton T. Patients' genes may influence quality of life after cancer chemotherapy. JAMA. 2004;292(6):673-4. https://doi.org/10.1001/jama.292.6. 673.

7. Sloan J, Zhao X. Genetics and quality of life. Curr Probl Cancer. 2006;30(6): 255-60. https://doi.org/10.1016/j.currproblcancer.2006.09.001.

8. Sprangers MAG, Thong MSY, Bartels M, Barsevick A, Ordonana J, Shi QL, et al. Biological pathways, candidate genes, and molecular markers associated with quality-of-life domains: an update. Qual Life Res. 2014;23(7): 1997-2013. https://doi.org/10.1007/s11136-014-0656-1.

9. Simon GR, Ismail-Khan R, Bepler G. Nuclear excision repair-based personalized therapy for non-small cell lung cancer: from hypothesis to reality. Int J Biochem Cell B. 2007;39(7-8):1318-28. https://doi.org/10.1016/j. biocel.2007.05.006.

10. Olaussen KA, Postel-Vinay S. Predictors of chemotherapy efficacy in nonsmall-cell lung cancer: a challenging landscape. Ann Oncol. 2016;27(11): 2004-16. https://doi.org/10.1093/annonc/mdw321.

11. Tan LM, Qiu CF, Zhu T, Jin YX, Li X, Yin JY, et al. Genetic polymorphisms and platinum-based chemotherapy treatment outcomes in patients with nonsmall cell lung Cancer: a genetic epidemiology study based meta-analysis. Sci Rep-Uk. 2017;7(1):5593. https://doi.org/10.1038/s41598-017-05642-0.

12. Vilmar A, Santoni-Rugiu E, Sørensen JB. ERCC1, toxicity and quality of life in advanced NSCLC patients randomized in a large multicentre phase III trial. Eur J Cancer. 2010;46(9):1554-62. https://doi.org/10.1016/j.ejca.2010.02.045.

13. Yin J, Vogel U, Ma Y, Qi R, Wang H. HapMap-based study of the DNA repair gene ERCC2 and lung cancer susceptibility in a Chinese population. Carcinogenesis. 2009;30(7):1181-5. https://doi.org/10.1093/carcin/bgp107.

14. Kim SH, Lee GW, Lee MJ, Cho YJ, Jeong YY, Kim HC, et al. Clinical significance of ERCC2 haplotype-tagging single nucleotide polymorphisms in patients with unresectable non-small cell lung cancer treated with firstline platinum-based chemotherapy. Lung Cancer. 2012;77(3):578-84. https:// doi.org/10.1016/j.lungcan.2012.04.016

15. Su T, Sun H, Lu XF, He C, Xiao L, He JW, et al. Genetic polymorphisms and haplotypes of BRCA1 gene associated with quality of life and survival among patients with non-small-cell lung cancer. Qual Life Res. 2020;29(10): 2631-40. https://doi.org/10.1007/s11136-020-02509-2.

16. Thomas G, Sinville R, Sutton S, Farquar H, Hammer RP, Soper SA, et al. Capillary and microelectrophoretic separations of ligase detection reaction products produced from low-abundant point mutations in genomic DNA. Electrophoresis. 2010;25(10-11):1668-77.

17. Zung WW. A rating instrument for anxiety disorders. Psychosomatics. 1971; 12(6):371-9. https://doi.org/10.1016/S0033-3182(71)71479-0.

18. Zung WW. A self-rating depression scale. Arch Gen Psychiatry. 1965;12(1): 63-70. https://doi.org/10.1001/archpsyc.1965.01720310065008. 
19. Aaronson NK, Ahmedzai S, Bergman B, Bullinger M, Haes JC. The European Organization for Research and Treatment of Cancer QLQ-C30: a quality-oflife instrument for use in international clinical trials in oncology. J Natl Cancer Inst. 1993;85(5):365-76. https://doi.org/10.1093/jnci/85.5.365.

20. Bergman B, Aaronson NK, Ahmedzai S, Kaasa S. The EORTC QLQ-LC13: a modular supplement to the EORTC core quality of life questionnaire (QLQC30) for use in lung cancer clinical trials. Eur J Cancer 1994;30A(5):635-42. https://doi.org/10.1016/0959-8049(94)90535-5.

21. Peter F, Simon W, Desmond C. EORTC QLQ-C30 Reference Values; 2008.

22. Barrett JC, Fry BA, Maller JB, Daly MJ. HAPLOVIEW: analysis and visualization of LD and haplotype maps. Bioinformatics. 2005;21(2):263-5. https://doi. org/10.1093/bioinformatics/bth457.

23. Ettinger DS, Akerley W, Borghaei $\mathrm{H}$, Chang AC, Hughes M. Non-small cell lung Cancer, version 6.2015. J Natl Compr Cancer Netw. 2013;11(6):645-53. https://doi.org/10.6004/jnccn.2013.0084.

24. Hamilton $G$, Rath B. Pharmacogenetics of platinum-based chemotherapy in non-small cell lung cancer: predictive validity of polymorphisms of ERCC1. Expert Opin Drug Metab Toxicol. 2018;14(1):17-24. https://doi.org/10.1080/1 7425255.2018 .1416095$.

25. Zulfan Z, Susanne V, Elise S, Geoffrey L, Bruce C. Genetic variations and cisplatin nephrotoxicity: a systematic review. Front Pharmacol. 2018;9:1111. https://doi.org/10.3389/fphar.2018.01111.

26. Grenda A, Bach J, Krawczyk P, Nico M, Milanowski J. P2.01-44 promoter polymorphisms of TOP2A and ERCC1 genes as predictive factors for chemotherapy in non-small cell lung cancer patients. J Thorac Oncol. 2019; 14(10):S656.

27. Anoushirvani AA, Aghabozorgi R, Ahmadi A, Arjomandzadegan M, Khalili S, Sahraei M, et al. The relationship between rs3212986C >a polymorphism and tumor stage in lung cancer patients. Cureus. 2019;11(4):e4423. https://doi. org/10.7759/cureus.4423.

28. Dong Y, Xiao-Hui L, Wei D, Xin-Jian X, Xi-Yan W. Contribution of DNA repair xeroderma pigmentosum group $D$ genotypes to pancreatic cancer risk in the Chinese Han population. Genet Mol Biol. 2017:41(1):18-26.

29. Chen S, Villeneuve L, Jonker $D$, Couture F, Guillemette C. ABCC5 and ABCG1 polymorphisms predict irinotecan-induced severe toxicity in metastatic colorectal cancer patients. Pharmacogenet Genomics. 2015;25(12):573-83. https://doi.org/10.1097/FPC.0000000000000168.

30. Yan X, Chen X, Li M, Zhang P. Prevalence and risk factors of anxiety and depression in Chinese patients with lung cancer:a cross-sectional study. Cancer Manag Res. 2019;11:4347-56. https://doi.org/10.2147/CMAR.S202119.

31. Yang GS, Kumar S, Dorsey SG, Starkweather AR, Kelly DL, Lyon DE. Systematic review of genetic polymorphisms associated with psychoneurological symptoms in breast cancer survivors. 2019;27(2):351-71. https://doi.org/10.1007/s00520-018-4508-3.

32. Young EE, Kelly DL, Shim I, Baumbauer KM, Lyon DE. Variations in COMT and NTRK2 influence symptom burden in women undergoing breast Cancer treatment. Biol Res Nurs. 2017;19(3):318-28. https://doi.org/10.1177/1 099800417692877

33. Min J. Koh, Hei-Cheul, Jeung, Kee, Namkoong, Hyun, Cheol, Chung: influence of the $\{\{B D N F \backslash\}$ Val66Met polymorphism on coping response to stress in patients with advanced gastric cancer. J Psychosom Res. 2014;77(1): 76-80. https://doi.org/10.1016/j.jpsychores.2014.04.008.

34. Schillani G, Martinis E, Capozzo MA, Era D, Giraldi T. Psychological response to cancer: role of 5-HTTLPR genetic polymorphism of serotonin transporter. Anticancer Res. 2010;30(9):3823-6.

35. Schillani G, Era D, Cristante T, Mustacchi G, Richiardi M, Grassi L, et al. 5HTTLPR polymorphism and anxious preoccupation in early breast cancer patients. Radiol Oncol. 2012;46(4):321-7. https://doi.org/10.2478/v10019-0120024-0.

\section{Publisher's Note}

Springer Nature remains neutral with regard to jurisdictional claims in published maps and institutional affiliations.

Ready to submit your research? Choose BMC and benefit from:

- fast, convenient online submission

- thorough peer review by experienced researchers in your field

- rapid publication on acceptance

- support for research data, including large and complex data types

- gold Open Access which fosters wider collaboration and increased citations

- maximum visibility for your research: over $100 \mathrm{M}$ website views per year

At BMC, research is always in progress.

Learn more biomedcentral.com/submissions 